\begin{tabular}{|c|l|}
\hline Title & A rea selective microscale metall ization on porous anodic oxide film of al uminium \\
\hline Author(s) & Jha, Himendra; Kikuchi, Tatsuya; Sakairi, Masatoshi; Takahashi, Hideaki \\
\hline Citation & $\begin{array}{l}\text { Electrochemistry Communications, 977), 1596-1601 } \\
\text { https://doi.org/10.1016/.elecom.2007.03.003 }\end{array}$ \\
\hline Issue Date & $2007-07$ \\
\hline Doc URL & http://hdl.handle.net/2115/27968 \\
\hline Type & article (author version) \\
\hline File Information & ECc9-7.pdf \\
\hline
\end{tabular}

Instructions for use 


\title{
Area-selective Microscale Metallization on Porous Anodic Oxide Film of Aluminium
}

\author{
Himendra Jha*, Tatsuya Kikuchi*, Masatoshi Sakairi, and Hideaki Takahashi
}

\begin{abstract}
A new method for micropatterning of metallic patterns on porous anodic oxide film of aluminium is described. The porous anodic oxide film was impregnated with organic dye and palladium ions before the hydrothermal pore-sealing. The surface layers formed during the pore-sealing, i.e. outer acicular hydroxide layer and a compact intermediate sub-layer trap the palladium ion underneath the layers. Exposing the palladium enriched area by the help of laser beam followed by electroless nickel deposition results the deposition of nickel on the laser-exposed part. Thickness of the deposits can be up to about $2-3 \mu \mathrm{m}$, after about the 20 min of immersion in electroless nickel plating bath. The metallic micropatterns, formed by the method are crack free, smooth and uniform over extended length.
\end{abstract}

Keywords: Anodizing; Pore-sealing; Laser patterning; Area-selected deposition; Metallic micropatterns.

\section{Introduction}

Microscale metallic patterns on various types of surfaces are of prime importance in many fields of technology, and enable the rapidly progressing miniaturization of components. The potential applications of metallic micropatterning include microelectronics, lab-on-chips, sensors, medical technologies and others. Micrometallic patterns on non-conducting surfaces, such as polymers, plastics, glasses, and ceramics are the topic of keen interest in both the scientific research community and microelectronic industry. Various methods based on masking, direct writing processes, and electrochemical techniques have been successfully applied for microscale metallic patterning of insulator surfaces [1-3]. Meanwhile, several laser-assisted direct processes have been established to generate metallic micropatterns on various insulators. The most often used techniques are laser activation for successive electroless plating [4], laser-assisted chemical vapour deposition (LCVD) [5], laser-induced forward transfer (LIFT) [6], and others. Further, research has been undergoing to develop and to improve the methods and compatibility of the techniques on various types of substrates.

Porous anodic oxide film of aluminium is wellestablished in various fields of nanotechnology. Highly ordered and uniform porous layer of anodic oxide film provides an ideal template for the fabrication of various nanostructures. The porous anodic oxide film formed on aluminium, prepared by anodizing in oxalic acid solution, is close to leucosapphire or glass ceramics, which are widely used in microelectronics. It also has sufficient mechanical strength and stability in extreme environments that make it suitable for the subsequent fabrication of hybrid integrated circuits [7]. Taking advantage of the high insulation ability of anodic oxide film formed on aluminium substrate by anodizing, various application have been reported in the past few decades [8-11]. Recently, thick porous anodic oxide film has been recognized as a promising material for the fabrication of various micro devices [12-14]. In these contexts, fabrication of metallic micropatterns on the anodic oxide film of aluminium, with a simple, precise, and cost-effective method is of keen interest in many areas of microelectronic industry as well as in various research processes.

Accordingly, in the present communication, we have demonstrated a novel approach for microscale metallization on anodic oxide film of aluminium by laser-assisted exposure of trapped seeds for electroless metal plating.

\section{Experimental}

Specimen: Highly pure aluminium plate (99.99 wt.\%), 350 $\mu \mathrm{m}$ thick, was cut to $20 \times 18 \mathrm{~mm}^{2}$ rectangular plates with a narrow handle. The specimens were ultrasonically cleaned in ethylalcohol for 10 minutes, and then electropolished in $78 \mathrm{vol} . \%$ $\mathrm{CH}_{3} \mathrm{COOH}+22$ vol. $\% \mathrm{HClO}_{4}$ solution for $5 \mathrm{~min}$ at a constant voltage of $28 \mathrm{~V}$, bellow $283 \mathrm{~K}$. Different steps for the microscale metallization on porous anodic oxide film of aluminium is illustrated in Fig. 1(a).
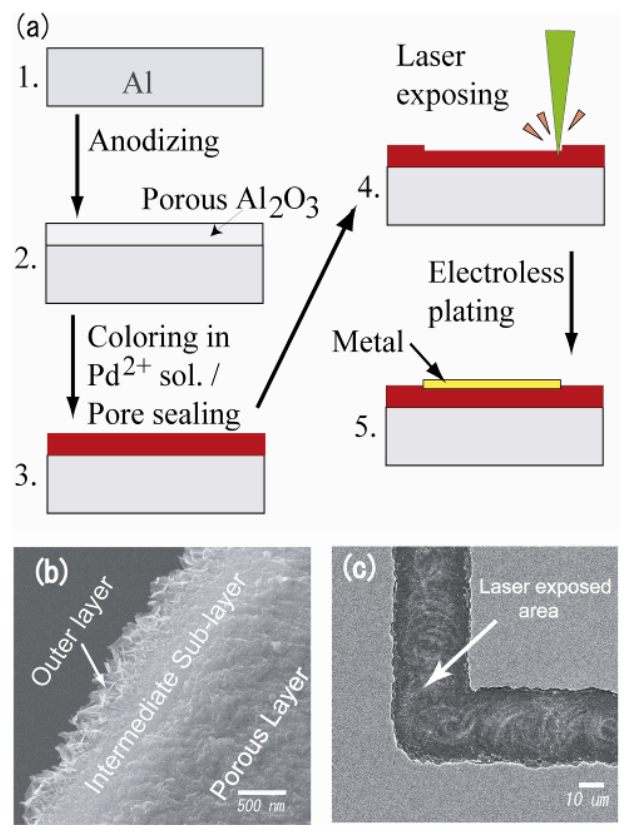

Figure 1: (a) schematic outline of the different steps of the laserassisted exposure of trapped seeds for electroless metal plating on anodic oxide film of aluminum. (b) Cross-section of outer surface of the anodic oxide film, after hydrothermal pore sealing (step 3 in (a)). The figure shows an outer acicular layer, a compact intermediate sublayer, and the inner bulk of the film. (c) Laser exposed area, by removing the upper layers of the anodic oxide film (step 4 in (a)).

[*] Lab. of Interface Microstructure Analysis Division of Materials Science and Engineering, Graduate School of Engineering, Hokkaido University, Kita-13 Nishi-8, Kita-Ku, Sapporo 060-8628, Japan

E-mail: himendra@elechem1-mc.eng.hokudai.ac.jp (H. Jha) kiku@elechem1-mc.eng.hokudai.ac.jp (T. Kikuchi)

Tel: + 81-11-706-7112 ; Fax: + 81-11-706-7881 
Anodizing: The specimens were anodized in $0.22 \mathrm{M} \mathrm{H}_{2} \mathrm{C}_{2} \mathrm{O}_{4}$ solution at $293 \mathrm{~K}$ for $2 \mathrm{~h}$, with a constant current of $100 \mathrm{Am}^{-2}$, to obtain about $32 \mu \mathrm{m}$ thick porous anodic oxide film on the aluminium substrate.

Colouring and pore sealing: After anodizing, the specimens were immersed in 25 vol. $\%$ of $8.9 \times 10^{-4} \mathrm{M} \mathrm{Pd}\left(\mathrm{CH}_{3} \mathrm{COO}\right)_{2}$ solution $\left[\mathrm{Pd}\left(\mathrm{CH}_{3} \mathrm{COO}\right)_{2}\right.$ was dissolved in $\left.10 \% \mathrm{CH}_{3} \mathrm{COOH}\right]+$ 75 vol. $\%$ of $0.029 \mathrm{M}$ Alizarin red S solution at $333 \mathrm{~K}$ for $300 \mathrm{~s}$. Then the specimens were subjected to pore-sealing in boiling doubly distilled water for $20 \mathrm{~min}$.

Laser assisted exposure: The anodic oxide film was irradiated with a Q-switched, second harmonic, pulsed Nd:YAG laser (Spectra Physics; GCR-100 series), with $532 \mathrm{~nm}$ wavelength, 8 ns pulse width, and $50 \mathrm{~Hz}$ frequency. The laser beam was passed through a rectangular diaphragm before focusing on the surface of the anodic oxide film with a convex lens. The laser irradiation was carried out in a plastic cell with a quartz window. The cell was either filled with $0.19 \mathrm{M} \mathrm{NaH} \mathrm{PO}_{2}$ at $\mathrm{pH}$ 4.5 , or with nickel electroless solution $\left(0.13 \mathrm{M} \mathrm{NiSO}_{4}, 0.27 \mathrm{M}\right.$

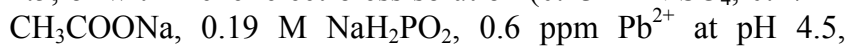
adjusted by $\mathrm{H}_{2} \mathrm{SO}_{4}$ ). The power density of the irradiated laser beam was measured just before focusing by the lens and fixed at $62 \mathrm{~mW} / \mathrm{cm}^{2}(2 \mathrm{~mW})$. The velocity of the 3D movable stage (KOHZU; PK 569-B) was 30 or $40 \mu \mathrm{m} / \mathrm{s}$ in two dimensions.

Electroless Plating: After laser irradiation, the specimen was quickly transferred to the electroless plating bath composed of $0.13 \mathrm{M} \mathrm{NiSO}_{4}, 0.27 \mathrm{M} \mathrm{CH}_{3} \mathrm{COONa}, 0.19 \mathrm{M} \mathrm{NaH}_{2} \mathrm{PO}_{2}, 0.6$ ppm $\mathrm{Pb}^{2+}$ and $\mathrm{pH} 4.5$ adjusted by $\mathrm{H}_{2} \mathrm{SO}_{4}$; the temperature of the baths was fixed at $353 \mathrm{~K}$.

Analysis: The metallic patterns on the anodic oxide film on aluminium were analyzed by a confocal scanning laser microscope, CSLM (Lasertec, 1LM21D), a field emission scanning electron microscope, FE-SEM (JEOL, JSM-6500F) equipped with EDS, and X-ray photoelectron spectroscopy, XPS (JEOL, JPS-9010MC).

\section{Results and Discussion}

Anodizing of aluminium for $2 \mathrm{~h}$ forms about $32 \mu \mathrm{m}$ thick porous anodic oxide film. Fig. 1 (b) shows the crosssection of outer surface of the anodic oxide film after colouring followed by hydrothermal pore-sealing. Highly crystalline, acicular layer on the outermost surface and compact intermediate sub-layer are clearly seen in the figure. Similarly, Fig. 1(c) shows the surface of the anodic oxide film, after removal of the surface layers, selectively, with the help of laser beam. Here the depth of the carved on the surface is about $1-1.2 \mu \mathrm{m}$.

During the pore sealing, boiling hot water penetrates the pores which cause anhydrous oxide to dissolve from the pore walls, forming aquo-hydroxo complexes, that on saturation precipitate, and this result in the plugging of the pores, as well as formation of the acicular crystalline hydroxide layer on the film surface. A continuous and compact intermediate sub-layer is also formed just beneath the outer acicular layer, as shown in Fig. 1(b) [15-19]. The formation of an outer acicular layer and intermediate sub-layer traps the palladium acetate, (which was impregnated during the colouring), underneath the film surface. A previous study found that, colouring followed by pore-sealing, strongly enhances the light absorption by the film; ensuring that the film surface can be easily patterned by using a laser beam [20]. Irradiating the surface with a low power laser beam, both the outer acicular layer and intermediate sub-layer are removed selectively, as shown in Fig. 1(c). The removal of the layers allows the porous layer to be exposed at the irradiated part.

Figure 2 shows FE-SEM images of the laser-exposed area after immersion in an electroless nickel plating bath for different periods. A laser beam with a power density of 62 $\mathrm{mW} / \mathrm{cm}^{2}$ and laser scanning speed $40 \mu \mathrm{m} / \mathrm{s}$ was used to expose the porous layer. Under these conditions, the depth of the laser-exposed area was found to be about $1.2 \mu \mathrm{m}$. Figure 2 $(a$, and $b$ ) shows the deposition in the laser exposed area, after 5 min of electroless plating. It can be seen that the deposition is not uniform, and nickel is predominantly deposited away from the edges of the exposed area. Fig. 2(b)
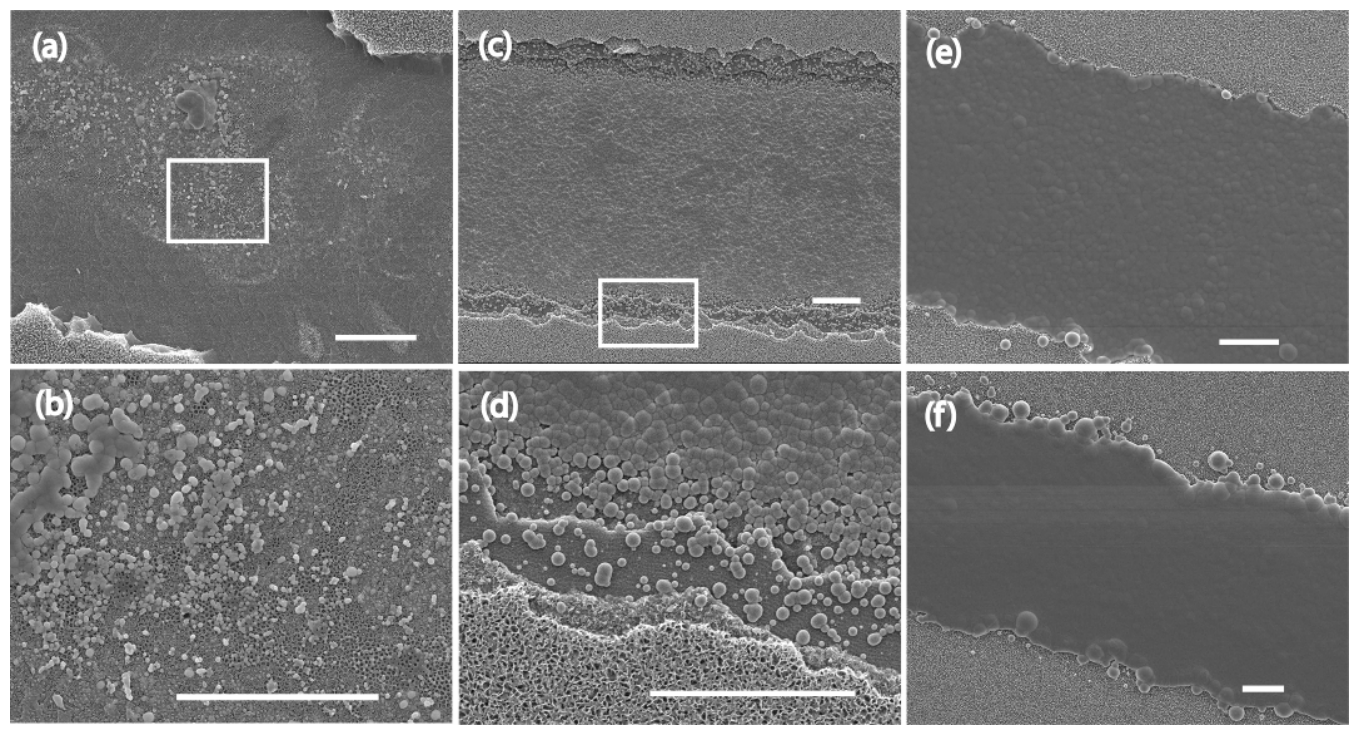

Figure 2: FE-SEM images of the laser-exposed part of an anodic oxide film of aluminium after different times of electroless nickel plating. (a) After immersion for $5 \mathrm{~min}$; (b) Magnified view of the boxed area in (a). (c) After 10 min of electroless deposition, a thin Ni-P layer deposited uniformly across the exposed area; (d) Magnified view of the boxed area in (c). (e) After 18 min of electroless deposition. (f) After $25 \mathrm{~min}$ of electroless deposition. (All the scale bars are $5 \mu \mathrm{m}$ ). 
(a)

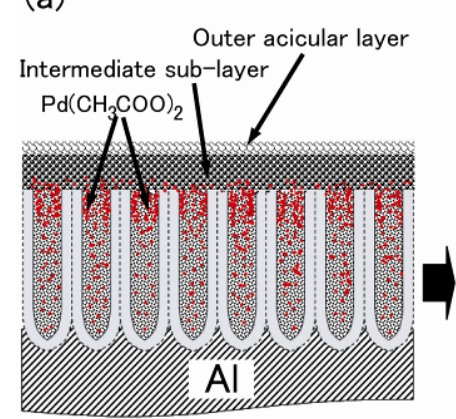

(b)

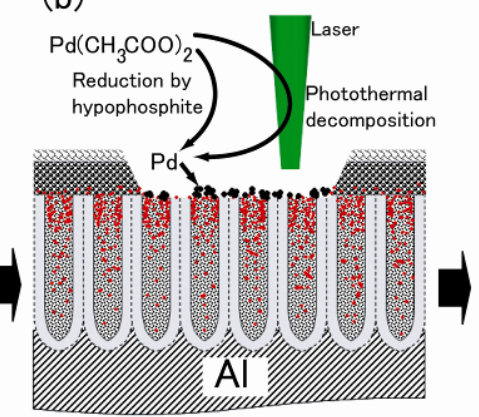

(c)

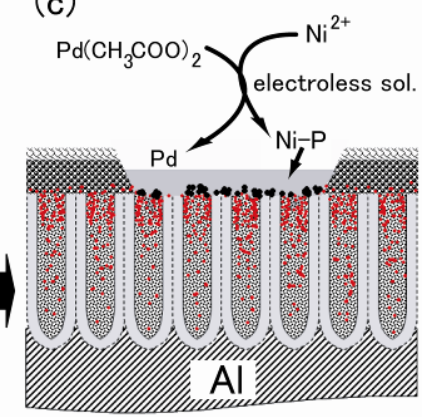

Figure 3: Diagrammatic representation of the mechanism of the various steps. (a) Trapping of palladium acetate underneath the surface. (b) Formation of palladium seeds during laser exposure. (c) Nickel deposition at the laser exposed area inside the electroless bath. (Figures not to scale)

shows hexagonal cell network, at the laser irradiated part, suggesting that the porous layer of the film is almost completely exposed. After $10 \mathrm{~min}$ of immersion in the electroless plating bath, uniform deposition has taken place across the laser irradiated area, as shown in Fig. 2 (c). The deposited nickel is dense and smooth, except at the edges, where it is less densely deposited, as shown in Fig. 2(d). It should be noted that, the deposition takes place selectively in the laser-irradiated area only, leaving the remaining surface covered with acicular hydroxide. Deposition at this stage can be clearly seen even by the naked eye. After deposition for about 18 min under the same conditions, the laser exposed area was completely filled with nickel deposit, as in Fig. 2 (e). The deposition is uniform and smooth across the laserexposed area, and there is no deposition on the nearby film surface. Neither cracks nor noticeable defects are observed on the deposited surface. Further increases in the deposition time, shows deposition which tends to spread beyond the laser exposed area onto the adjacent film surface, as shown in Fig. 2 (f), which shows the situation after $25 \mathrm{~min}$ of electroless nickel deposition.

It was observed that increases in the concentration of palladium acetate in the colouring solution, to some extent, accelerate the deposition rate. However, higher concentrations cause a hyper activation of the surface, which leads to undesired deposition towards the edge, and then on to the nearby film surface. It must be emphasized that, a precise removal of the outer acicular layer as well as the compact intermediate sub-layer, from the laser irradiated surface is a key requirement of this technique. In our specimen preparation procedure, formation of a 1 to $1.2 \mu \mathrm{m}$ deep depression on the surface by laser irradiation shows the optimum conditions for deposition. Therefore, the laser power and scanning speed must be adjusted to meet the depth requirements.

In the present technique, the formation of an outer acicular layer and a compact intermediate sub-layer by dissolution and precipitation is considered to trap the palladium acetate inside the film. The experiments here found that: a) when the specimen was immersed in the electroless solution, without exposing the porous layer by laser irradiation, it did not show any deposition even after prolonged immersion $(>2 \mathrm{~h}$ ). Removing only the outer acicular layer (usually $<0.8 \mu \mathrm{m}$ ), also, did not result in metal deposition in the laser exposed area. b) Removal of the outer acicular layer as well as the compact intermediate layer (typically down to 1 to $1.2 \mu \mathrm{m}$ below the surface) enables a rapid deposition in the laser exposed area, immediately after only a few minutes of immersion in the electroless nickel plating bath. c) Increasing the depth of the exposed area to about $5 \mu \mathrm{m}$ or more, the exposed area either did not show deposition or limited deposition at the edge near the film surface was observed. This evidence suggests that, the palladium acetate is preferentially enriched near the interface of the compact intermediate layer with the porous layer, as shown in Fig. 3 (a). Therefore, it was assumed that, the region beneath the film surface is activated during the specimen preparation, by impregnating it with palladium acetate, which is then exposed to the electroless solution by the low power laser beam. Here the outer acicular layer and compact intermediate sub-layer, on top of a thick porous layer, acts as a mask for the electroless metal deposition, facilitating area-selective metal deposition on the film surface.

It has been reported that, the thin palladium acetate layer, on a substrate undergoes photo-thermal decomposition into metallic palladium, when irradiated with a laser beam [21-23]. Palladium (II) in contact with hypophosphite solution can be also reduced to metallic palladium [24, 25]. We found that, anodic oxide film, that had been soaked with palladium acetate on the surface, allowed metal to be deposited on the film surface immediately after immersion in the electroless nickel bath, i.e. the palladium acetate on the surface acts as a catalyst in the plating of nickel, without any photo-thermal treatment. An attempt was made to analyse the surface, with and without laser irradiation, by EDS and XPS but we were not successful in determining the distribution and chemical states of the palladium, due to the extremely low concentration of palladium or palladium ions on the surface. In the experiments, the specimen was irradiated in hypophosphite containing solutions. Overall it may be assumed that, the formation of palladium seeds in the laserirradiated area is due to photo-thermal decomposition as well as electrochemical reduction of the palladium ions, as suggested in Fig 3 (b). Once palladium seeds form at the laser irradiated surface, they act as nucleation sites for the electroless nickel deposition. The deposition is initiated over all the laser-exposed area after few a minutes of immersion in the electroless nickel bath, as shown in Fig 3 (c). Here also, there may be a reduction of palladium ions to palladium, if remaining palladium ions are exposed to the electroless solution.

Figure 4 shows CSLM images of metallic micropatterns on the anodic oxide film of aluminium. All the patterns were fabricated, using a $62 \mathrm{~mW} / \mathrm{cm}^{2}$ laser beam with $40 \mu \mathrm{m} / \mathrm{s}$ of scanning speed. Figure 4 (a) shows metallic lines on the oxide 


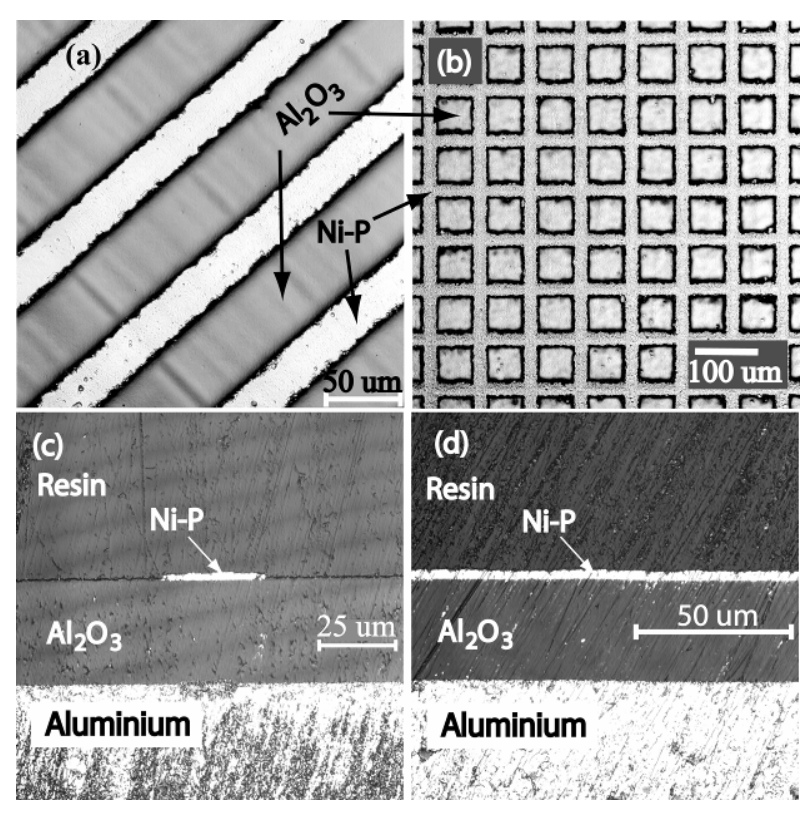

Figure 4: Metallic micropatterns on anodic oxide film of aluminium. a) Ni-P lines on the oxide film. b) Metallic network of Ni-P on the oxide film. c) Cross-section of a metallic line across the line width, and d) across the line length.

film at regular intervals, formed after 10 min of immersion in the electroless nickel bath. The lines are about $25 \mu \mathrm{m}$ wide and about $1 \mu \mathrm{m}$ thick. The pattern is uniform and has good edge definition. The width of the metallic pattern can be changed by adjusting the size of the beam spot on the film surface. The technique is flexible to the substrate shape and structures, as the movement of the laser beam across the specimen can be controlled by computer aided design. Fig. 4(b) shows the ordered metallic network on the anodic oxide film of aluminium. The metallic pattern shows uniform deposition and good edge definition, after immersion for $10 \mathrm{~min}$ in the electroless plating bath. Longer deposition $(>15 \mathrm{~min})$ resulted in a lateral spreading of the deposition near the crossing points of two metal lines, distorting the shape of the pattern. Similarly, a vertical cross-section of the metallic micropattern, after 20 min of immersion in an electroless nickel bath was observed by CSLM, and is shown in Fig. 4 (c-d). Figure 4(c) shows the cross section of a metallic line along its width, while Fig 4(d) shows a section along its length. It can be seen that the metal is deposited quite homogeneously and continuously on the film surface over the extended length of the pattern. The deposited metallic patterns do not contain cracks.

The present method can make a good quality of metallic micropattern on anodic oxide film of aluminium, which is free from cracks, and highly uniform with good edge definition. The method is simple and environmentally friendly i.e. no use of toxic chemicals. We hope this method can be useful for the fabrication of various microelectronic components and microdevices.

\section{Conclusion}

A successful technique for microscale metallization on anodic oxide film of aluminium is demonstrated. The patterns formed by the technique shows uniform deposition of metal over extended lengths and up to about $2-3 \mu \mathrm{m}$ of the metal can be deposited without any type of defect. Such a microscale metallic film offers excellent potential for the fabrication of various types of microelectronic components and microdevices.

\section{Acknowledgements}

The research was partially supported by a Grant-in-Aid from the Ministry of Education, Culture, Sports, Science and Technology, Japan, and Light Metal Education Foundation of Japan. The authors would like to thank Mr. Kazuhiro Nagahara for his co-operation during the work.))

\section{References}

[1] M. Geissler, and Y. Xia, Adv. Mater. 16 (2004) 1249.

[2] V. Fleury, W. A. Watters, L. Allam, and T. Devers, Nature $416(2002) 716$.

[3] M. J. Madou, Fundamentals of Microfabrication: The Science of Miniaturization, $2^{\text {nd }}$ ed., CRC Press, Boca Raton, FL, 2001.

[4] G.A. Shafeev, Appl. Phys. A 67 (1998) 303.

[5] S.D. Allen, J. Appl. Phys. 52 (1981) 6501.

[6] T. Sano, H. Yamada, T. Nakayama, and I. Miyamoto, Appl. Surf. Sci. 186 (2002) 221.

[7] N.I. Mukhurov, G.I. Efremov, and I.F. Kotova, Proceedings of the Technical Digest of IVMC'97, Kyongju, Korea, August 17-21, 1997.

[8] R. I. Larson, US Patent 5774336, 1998.

[9] R.P. McMonagle, US Patent 4525247, 1985.

[10] G.A. Efermov, N.I. Mukhurov, and V.I.Kovalevsky, Proceedings of the Third International EuroConference on Advanced Semiconductor Devices and Microsystems (ASDAM 2000), Smolenice Castle, Slovakia, October 16 18, 2000.

[11] R. Remsburg, US Patent 5917157, 1999.

[12] K.I. Delendik, and O. L. Voitik, Proceeding of SPIE, MICRO/MEMS 2001, 4592, 2001

[13] T. Kikuchi, M. Sakairi and H. Takahashi, J. Electrochem. Soc. 150 (2003) C 567.

[14] M. Sakairi, M. Yamada and H. Takahashi, Electrochem. Soc. Proc.19 (2004) 359.

[15] H. Takahashi, ASM Handbook vol. 13A, ASM International, 2003, p. 736.

[16] K. Wefers, Aluminium 49 (9) (1973) 622

[17] G. C. Wood and J. P. O'Sullivan, J. Electrochem. Soc. 116 (1969) 1351.

[18] R. C. Spooner, Plating 58 (1971) 449.

[19] V. Lopez, M.J. Bartolome, E. Escudero, E. Otero, and J.A. Gonzales, J. Electrochem. Soc. 153 (3) (2006) B75.

[20] H. Jha, T. Kikuchi, M. Sakairi, and H. Takahashi, Electrohimica. Acta 52 (2007) 4724-4733

[21] Y. Zhang, and M. Stuke, Appl. Surf. Sci. 46 (1990) 153.

[22] M. E. Gross, A. Appelbaum, and P. K. Gallagher, J. Appl. Phys. 64 (4) (1987) 1628.

[23] J. Y. Zhang, and I. W. Boyd, Thin Solid Film 318 (1998)

[24] M. Charbonnier, M. Alami, and M. Romand, J. Appl. Electrochem. 28 (1998) 449.

[25] T. Khoperia, T. J. Tabatadze, and T. I. Zedgenidze, Electrochim. Acta 42 (1997) 3049. 
